\title{
Addressing anemia among women in India - an informed intervention using Facebook Ad Manager
}

\author{
Nadia Diamond-Smith ${ }^{1}$, Avery E. Holton ${ }^{2}$, Sarah Francis ${ }^{3}$, Drew Bernard ${ }^{3}$ \\ ${ }^{1}$ Department of Epidemiology and Biostatistics, Institute for Global Health Sciences, University of California, San Francisco, CA, USA; ${ }^{2}$ Department \\ of Communication, University of Utah, Salt Lake City, UT, USA; ${ }^{3}$ Upswell, Seattle, WA, USA \\ Contributions: (I) Conception and design: All authors; (II) Administrative support: All authors; (III) Provision of study materials or patients: S Francis, \\ D Bernard; (IV) Collection and assembly of data: S Francis, D Bernard; (V) Data analysis and interpretation: All authors; (VI) Manuscript writing: All \\ authors; (VII) Final approval of manuscript: All authors. \\ Correspondence to: Nadia G. Diamond-Smith. Department of Epidemiology and Biostatistics, Institute for Global Health Sciences, University of \\ California, San Francisco, CA, USA. Email: nadia.diamond-smith@ucsf.edu.
}

Background: Women in India continue to have high rates of anemia, especially in critical periods of adolescence and pregnancy. Anemia persists despite decades of government programs aimed at combatting anemia, including through the provision of iron folic acid tablets (IFA). With growing access to mobile phones and social media, even among women, mobile interventions hold potential for influencing knowledge and behaviors. Social media consumption, including on Facebook, is high in India. However, little research has explored if women can be reached with health messages using social media, if data can be collected through this mechanism, and if interventions using social media impact knowledge and behaviors surrounding important health issues such as anemia. The aims of this study were to test an advertising campaign on Facebook about anemia and IFA to women, collect data through social media, and measure its impact.

Methods: A baseline survey and two follow-up surveys were sent to women via Facebook in 2019 in two states of India: Madhya Pradesh and Uttar Pradesh. Between each round of data collection, a set of advertisements based on gaps in knowledge and practices identified in the baseline on anemia and IFA were delivered to more than 3 million women on Facebook. Using this data, we analyze current knowledge and behaviors around anemia and IFA and look at differences by socio-demographics including age, Marital status, and pregnancy. Using logistic regression models, we then look for evidence of a significant change in knowledge and behaviors between rounds of data collection.

Results: We find that while general knowledge about anemia was high, especially related to its importance in pregnancy, misperceptions persist, such as that it makes babies large and delivery difficult. Only about $15 \%$ of the population was currently taking IFA, although nearly $50 \%$ noted that they had at some point. Younger women had lower levels of knowledge and practices. Findings about the impact of the Ad campaigns were mixed, with some indicators changing in positive and some in negative directions and no clear trend between surveys. Two indicators that were of high focus in the Ad campaigns changed in the desired direction after both ad campaigns (iron can make labor/delivery difficult and iron supplements are only for women who have anemia).

Conclusions: Overall, this study shows that a social media campaign about anemia has the potential to reach a large number of women in India, including young women, who are hard to reach if they are not in school or currently pregnant and seeing a physician. This study shows that it is possible to collect data from women through social media and measure the impact of an intervention. More research is needed to know if social media is an effective approach to actually change attitudes and behaviors related to anemia, or other important health concerns.

Keywords: Anemia; efficacy; Facebook; India; iron folic acid; social media 
Received: 26 November 2019; Accepted: 15 May 2020; Published: 05 October 2020.

doi: $10.21037 /$ mhealth-19-237a

View this article at: http://dx.doi.org/10.21037/mhealth-19-237a

\section{Introduction}

Anemia, a health condition diagnosed in individuals with low levels of iron and other vitamins in their blood, continues to represent global health concern (1). In particular, countries where food supplies naturally rich with iron, or where access to iron supplements and other forms of enrichment are limited, continue to struggle with anemia and its related health issues. India ranks among these (2). The most recent national estimates in India suggest that more than half of all women between 15- and 49-year-old suffer from anemia (3). Anemia is of particular concern in pregnancy, where is associated with adverse birth outcomes including preterm birth and low birth weight (4).

Indian government programs aimed to reduce anemia in pregnant women and adolescent girls have not had the desired impact on anemia rates, especially for adolescents (3). Women in India have low levels of empowerment and are not always able to leave the home, especially alone, to seek health care, or make decisions about their health even when they have knowledge (5). Girls' education and literacy rates still lag behind boys in India. Thus, even though programs exist in schools, a subset of girls may not be exposed to them if they are not currently in school (6). Finally, young women who are not in school and not pregnant may be entirely missed in current anemia prevention programs. Thus, reaching women in India outside of schools and pregnancy care/the health system is key. Innovative approaches, such as mHealth, hold potential to reach these vulnerable, hard to reach populations.

This study set out to analyze such an approach, using a multi-step intervention and Facebook Ad Manager to reach more than 8.4 million women over two periods of time in 2019 in India. This study first assessed the knowledge, attitudes, and behaviors of women in India with regards to anemia and iron-folic acid tablets (IFA), implemented a series of Facebook Ads meant to address knowledge, attitudes, and potential behaviors, and then used a followup survey to analyze the impact of those Ad interventions. The findings indicate that data collection through mobile applications is possible in this setting, including among hard to reach populations of young women, health interventions over Facebook hold potential for reaching women in India, and that gaps will remain in knowledge and practices around anemia and IFA consumption. More research is needed as to the ability of advertisements over Facebook to change knowledge, attitudes and practices around anemia and IFA in this setting.

\section{Background and literature}

Nearly half of pregnant women in India experience anemia according to the most recent Indian National Family Health Survey from 2015-16 (NFHS-4) (3). Other national surveys in India have estimated a higher prevalence among pregnant women, with some as high as $64 \%(3,7)$. In India, anemia is more notable among lactating women and young women, with some states suggesting that more than $90 \%$ of adolescent girls are anemic $(8,9)$. The latter is particularly critical given that anemia in adolescents is associated with physical and developmental delays, fertility related issues, and, due to early age at childbearing, can lead to anemiarelated complications during pregnancy (9).

IFA tablets are one of the most effective methods of combating anemia throughout the life course (10). As per the Indian government, IFA tablets are comprised of $0.5 \mathrm{mg}$ of folic acid and $100 \mathrm{mg}$ iron and 100 IFA tablets are to be distributed free of cost to women during pregnancy through the community health care worker network and primary health care centers $(11,12)$. However, according to NFHS4 , less than 1 in 3 pregnant women in India consume the recommended dosage of IFA during pregnancy (3). This despite a wealth of government programs that have been in place in India for decades: the National Nutritional Anemia Control Program began providing free IFA tablets to pregnant and breastfeeding women in the 1990s (13), the National Iron+ Initiative Program (NIPI) provides free IFA to children, adolescents, pregnant or lactating women, and women identified as "of a reproductive age (15-49 years), and the Weekly Iron and Folic Acid Supplementation Program (WIFS) provides free weekly IFA tablets to adolescents in schools (14)".

However, these programs have not been successful in reducing anemia broadly or in pregnant or adolescent women specifically, making the development of an intervention to improve anemia rates among these 
populations all the more significant. It is also important to highlight that these programs only target adolescent girls in school and pregnant women connected to health carethey miss a key population of adolescents out of school and young unmarried or recently married but not yet pregnant women. These women are often missed in interventions, yet are critically important because they are at high risk of pregnancy and they are often at low status in their household and communities, thus putting them at high risk of anemia as well $(15,16)$.

Aside from the official government programs, a number of interventions have tried with varied results to increase IFA consumption and reduce anemia in India. Many of these have involved health information, additions to existing government programs with supplemental counseling, and deworming or nutrition-supplementation. There is mounting evidence to suggest that the importance of social norms are significant and underutilized drivers of IFA consumption and the potential reduction of anemia in India. Many women and communities have misinformed perceptions about anemia (or its side effects) as well as its role in pregnancy. These include a perception that IFA has negative side effects on women and babies (weight gain, babies being too large, etc.), that taking IFA is not necessary, and that taking IFA is expensive or is already included in everyday diets $(5,17,18)$. Family and community members, and their beliefs about IFA and anemia, are key barriers (or facilitators) for consumption. For example, family members' misinformation about side effects can be a barrier to women being allowed to take IFA, even if the women themselves are interested.

Few studies have examined the effectiveness of mHealth interventions to improve anemia rates and IFA uptake. This is despite the promise of early mHealth health efforts in India including the use of text messages to assist those with tuberculosis (19), voice calls for those with diabetes (20), and mobile-based apps to connect with Indians living in rural areas (21). These and others studies have driven health researchers and practitioners to call for more consideration of mHealth tools in addressing major health issues in India (22). It should be noted that questions still remain about the use of social media for health campaigns, including the potential for sharing misleading and false information and also whether and how certain topics (such as sexual and reproductive health campaigns) should use a social media approach $(23,24)$. NFHS-4 found that almost half of women $(46 \%)$ reported that they had access to a mobile phone, and of these two-thirds could read a text-message (3).
This is at a time when India represents one of the most active countries on several social media platforms, including WhatsApp and Facebook. India has the largest number of Facebook users in the world-270 million as of July 2019-outpacing the United States by nearly 85 million users and representing approximately $10 \%$ of global users (25). Thus, Facebook provides a rich environment to evaluate knowledge, behaviors and attitudes about anemia and IFA and to implement and analyze the findings from a social media-based intervention.

The broad goal of this project was to develop, test, and document strategies for running effective social and behavioral change campaigns on social media through the practical application of campaigns focused on increasing the motivation of young women to consume IFA supplements in India. We hoped to reach a larger percentage of our target audience (up to $75 \%$ ) at least 5 times with relevant content. If the average engagement rate with our content was at least $5 \%$ (i.e., $5 \%$ of the people who receive a piece of content engage with it by sharing, commenting, or reacting), our target audience might demonstrate higher consumption of IFA, more accurate knowledge and less misinformation, and would report higher levels of motivation to consume IFA.

The first aim of this study was to evaluate knowledge, behaviors and attitudes about anemia and IFA in women in India using a social media data collection approach. The second aim was to use this data to develop an advertising campaign over social media, and evaluate the impact of this campaign on knowledge as well as IFA use, before and after our campaign.

\section{Methods}

In order to assess the knowledge and perceptions of IFA among women in India, we first developed a survey to gauge attitudes toward and knowledge about anemia and IFA. All of the questions were single choice (i.e., choose one from a list of options) and included questions such as "Have you taken an iron supplement in the last seven days?". The final survey included 21 total questions, including four demographic questions (age, Marital status, pregnancy status and state). Because some questions were dependent on the answers to other questions, a given respondent could answer between 19 and 21 questions. Most questions had the response categories of "Yes", "No" and "Unsure". For the analysis purposes, "unsure" responses were grouped with "no" responses.

The survey was initially developed in English, and 
Baseline: 3/14/19 -3/18/19

4,843 women responded to the advertisement and completed the first survey round, including 2,885 of respondents from Uttar Pradesh and 1,958 from Madhya Pradesh.

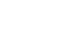

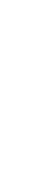

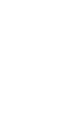

9

Campaign 1: 4/19/19-6/4/19

104 pieces of content types to test the creative direction for our future campaigns. Reached 1,151,471 members of the target audience with 570,382 likes, comments, and shares.
Survey 3: 8/28/19 - 8/29/19

A total of 6,004 women responded to the third survey round: 3,471 respondents from Uttar Pradesh and 2,533 from Madhya Pradesh. second survey round: 2,483 respondents from Uttar Pradesh and 1,321 from Madhya Pradesh.

Figure 1 For health.

translated into Hindi with the assistance of Rabbithole, an India-based creative firm. Rabbithole staff members that translated the survey were from Lucknow in Uttar Pradesh. The full list of questions, in both English and Hindi, can be found in http://cdn.amegroups.cn/static/application/5 2665 df58ef8008b68696b5c595dabd/mhealth-19-237a-Appendix A.xlsx.

Once the questions were finalized, surveys were created using Typeform, a cloud-based data collection app with surveys designed for mobile devices and social media platforms. Typeform also has Facebook Pixel and Google Analytics integration, which allowed for the gathering of data about how users interact with the survey. This can help inform future surveys and can also highlight any issues with survey completion as they arise. Bernard et al. [2019] describe this process in more detail (26).

Links to our survey were distributed using advertisements created and delivered through Facebook's Ad Manager. Ad Manager enabled ads to be targeted based on location, gender, and age (among a wide variety of other variables). The overall target audience for this study was women on Facebook in Madhya Pradesh and Uttar Pradesh between the ages 18 and 49. Madhya Pradesh and Uttar Pradesh states were selected for two reasons: (I) there is a high rate of Facebook penetration among our target audience and (II) organizations were actively working on the ground to insure IFA tablet availability. There is a total of 2,900,000 monthly active users (MAU) on Facebook in this demographic in Madhya Pradesh and 6,500,000 MAU on Facebook in this demographic in Uttar Pradesh. Over a 78 hour-period from
Mar 14, 2019 to Mar 18, 2019, a total of 4,843 women responded to the advertisement and completed the first survey round, including 2,885 of respondents from Uttar Pradesh and 1,958 from Madhya Pradesh. This initial survey established our baseline for our effort to leverage Facebook in order to increase knowledge of anemia and the motivation to take IFA (Figure 1).

With the baseline complete, Rabbithole developed 104 pieces of content to test the creative direction for our future campaigns. Each piece of content was designed to raise awareness about the signs of anemia and the importance of IFA. The content was a mix of still images and Gifs with all of the content copy in Hindi. We tested with the lower cost still images and Gifs first and once we understood what types of content and messages resonated with our target audience, we created videos and Facebook stories to further engage our audience.

Using the same age group and geographic location segments as the initial survey, we created 84 different Facebook ads using Facebook's Ad Manager. Facebook Ads Manager is Facebook's tool for creating ads, managing when and where they will run, and tracking the performance of advertising campaigns. On Facebook, a "campaign" can be any number of ads delivered to any number of target audiences with a specifically defined objective. Facebook then targets the distribution of your ads in a manner intended to maximize the value of your campaign. For this campaign we chose the Engagement objective because the primary goal of this study was to have women engage with content that might positively impact their knowledge about 
and attitudes toward anemia and IFA.

The campaign ran over a 6-week period during April and June 2019. In Madhya Pradesh, the campaign reached $1,151,471$ members of the target audience with 570,382 likes, comments, and shares. In Uttar Pradesh, the campaign reached 2,304,479 members of the target audience with $1,062,649$ likes, comments, and shares. This for a combined total of 3,455,950 members and 1,633,081 likes, comments, and shares.

After the first campaign, we re-ran the original survey following the same method. The second survey ran for 196 hours, from June 12, 2019 to June 15, 2019. A total of 3,804 women responded to the second survey round: 2,483 respondents from Uttar Pradesh and 1,321 from Madhya Pradesh.

Using the same age group and geographic location segments as the first ad campaign, we launched a second campaign with Facebook's Ad Messenger. The second campaign ran for 9 weeks between June 25, 2019 and August 27, 2019 and included 136 ads that were a mix of still and animated ads. For the second campaign, we reached 1,584,126 members of our target audience in Madhya Pradesh, with 1,003,468 likes, comments, and shares. In Uttar Pradesh, we reached 3,888,124 members of our target audience with 1,681,313 likes, comments, and shares. This for a combined total of 4,961,274 members and 2,684,781 likes, comments, and shares.

After the second campaign ended, we re-ran our original survey following the same method. Our 3rd survey ran for 14 hours, from August 28, 2019 to August 29, 2019. A total of 6,004 women responded to the third survey round: 3,471 respondents from Uttar Pradesh and 2,533 from Madhya Pradesh.

We then analyzed differences with $t$-tests in responses to survey responses from before the Facebook Ad Manager campaign and after the campaign. We then explored differences by age using chi2 tests. We also analyzed differences by other potentially important confounders including Marital status (Yes/No), having children (Yes/ No), being pregnant status (Yes/No), and state (Uttar Pradesh compared to Madhya Pradesh). Finally, we ran a series of logistic regression models, controlling for the above mentioned socio-demographic confounders, to explore whether there were significant differences pre and post each round of the intervention. Data was analysed using STATA 15.

This study received human subject approval from the University of California, San Francisco. No personal identifying information (such as names, emails, addresses, phone numbers) was collected from respondents and Facebook does not distribute any information about its users. Respondents did not receive an incentive for participation and could stop participation at any time. Facebook does not allow ads to be targeted to people under 18 , and the informed consent that respondents had to agree to before taking the survey stated that respondents had to be over 18 . However, we have no way to verify age and it is possible that the survey was shared to people under 18 .

\section{Results}

\section{Knowledge and practices}

Most women $(83.4 \%)$ were not taking IFA at the time of the survey, and this was not statistically significantly different between surveys (Table 1). However, more than half $(59.9 \%)$ had taken IFA at some point, and this was statistically significantly different between rounds. Most women knew that IFA prevented anemia (85.9\%), and this was significantly different between rounds. Significant differences were also seen in the percent of women that thought that pregnant women should take IFA (overall $87.7 \%)$, thought women under 20 should take it (34.2\% overall), that it made babies too large (10.2\% overall), that it was only for anemia (33.5\%), helped you do better at school (63.1\%), that it made babies healthier $(62.7 \%$ overall), that it made you stronger $(72.2 \%$ overall), that it led to a difficult labor $(7.3 \%$ overall) and that it made you gain weight $(7.9 \%$ overall). There was no significant difference in the percent that thought it helped you stay healthy ( $83.6 \%$ overall). There was also no significant difference in the percent that thought that IFA would be easy to obtain (80.3\%). It is important to note that some of these answers were quite low because of high proportions of women reporting that they were unsure/did not know.

\section{Differences by socio-demographics}

There were significant differences in responses by age group with younger women being less likely to have appropriate knowledge for every question asked, or currently taking iron, ever have taken iron, or thinking it was easy to obtain it (Table 2). The only item that was not significantly different by age was the knowledge question about whether IFA made you stronger. Similarly, unmarried women and women without children had lower knowledge and poorer 
Table 1 Knowledge, attitudes and behaviors in baseline, post-campaign 1 and post-campaign 2 surveys

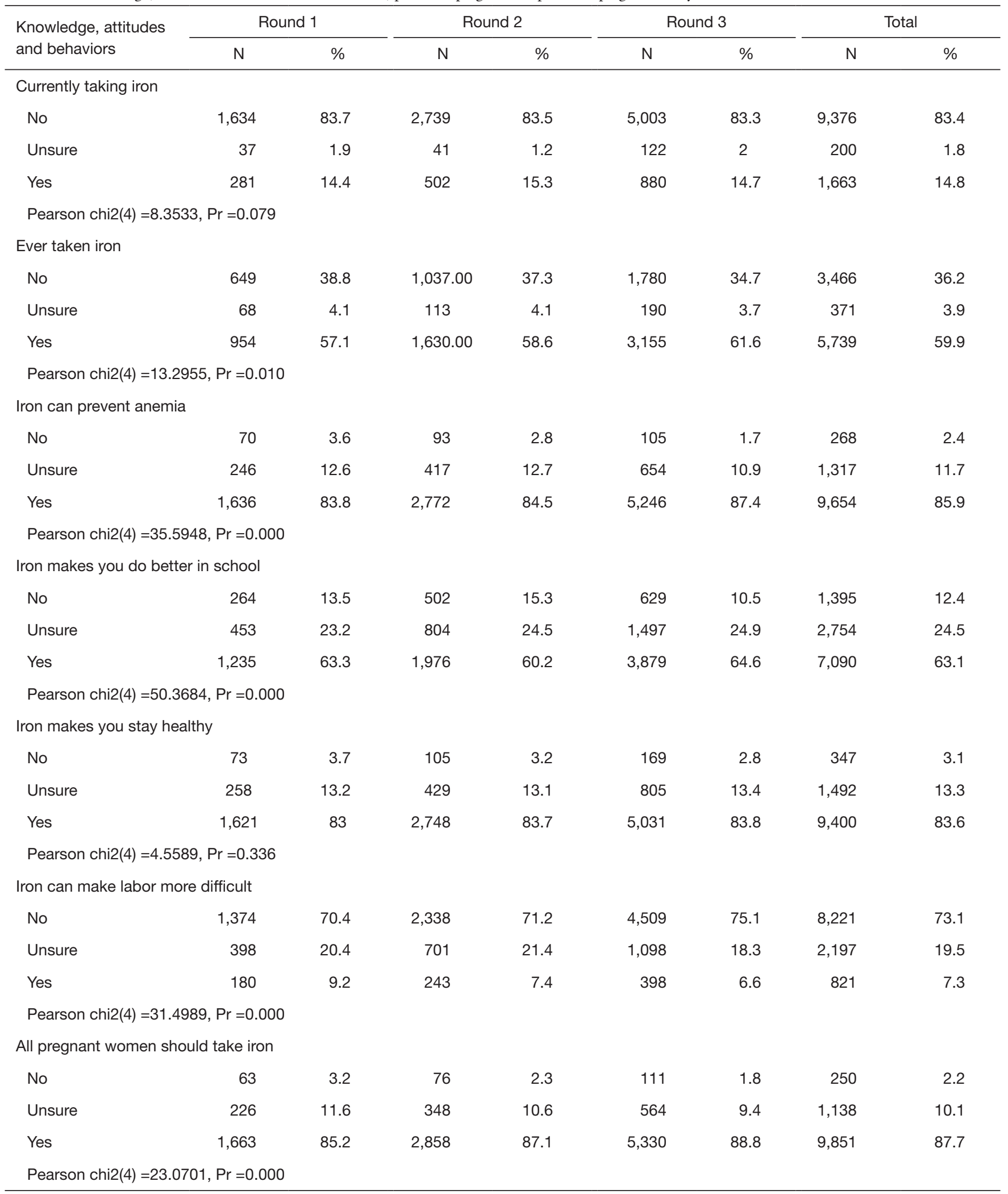

Table 1 (continued) 
Table 1 (continued)

\begin{tabular}{|c|c|c|c|c|c|c|c|c|}
\hline $\begin{array}{l}\text { Knowledge, attitudes } \\
\text { and behaviors }\end{array}$ & \multicolumn{2}{|c|}{ Round 1} & \multicolumn{2}{|c|}{ Round 2} & \multicolumn{2}{|c|}{ Round 3} & \multicolumn{2}{|c|}{ Total } \\
\hline \multicolumn{9}{|c|}{ Iron is only for women with anemia } \\
\hline No & 862 & 44.2 & 1,529 & 46.6 & 2,943 & 49 & 5,334 & 47.5 \\
\hline Unsure & 376 & 19.3 & 652 & 19.9 & 1,117 & 18.6 & 2,145 & 19.1 \\
\hline \multicolumn{9}{|c|}{ Pearson chi2 $(4)=17.5955, \operatorname{Pr}=0.001$} \\
\hline \multicolumn{9}{|c|}{ All women under 20 should take iron } \\
\hline No & 524 & 26.8 & 901 & 27.5 & 1,515 & 25.2 & 2,940 & 26.2 \\
\hline Unsure & 725 & 37.1 & 1,321 & 40.2 & 2,405 & 40 & 4,451 & 39.6 \\
\hline No & 157 & 8 & 291 & 8.9 & 441 & 7.3 & 889 & 7.9 \\
\hline Unsure & 376 & 19.3 & 695 & 21.2 & 1,164 & 19.4 & 2,235 & 19.9 \\
\hline Yes & 1,419 & 72.7 & 2,296 & 70 & 4,400 & 73.3 & 8,115 & 72.2 \\
\hline \multicolumn{9}{|c|}{ Pearson chi2(4) $=13.4719, \operatorname{Pr}=0.009$} \\
\hline \multicolumn{9}{|c|}{ Iron makes you gain weight } \\
\hline No & 1,281 & 65.6 & 2,122 & 64.7 & 3,887 & 64.7 & 7,290 & 64.9 \\
\hline Unsure & 502 & 25.7 & 878 & 26.8 & 1,686 & 28.1 & 3,066 & 27.3 \\
\hline Yes & 214 & 11 & 335 & 10.2 & 596 & 9.9 & $1,145.00$ & 10.2 \\
\hline \multicolumn{9}{|c|}{ Pearson chi2 $(4)=11.4570, \operatorname{Pr}=0.022$} \\
\hline \multicolumn{9}{|c|}{ Iron makes babies healthier } \\
\hline No & 231 & 11.8 & 378 & 11.5 & 605 & 10.1 & 1,214 & 10.8 \\
\hline Unsure & 548 & 28.1 & 897 & 27.3 & 1,530 & 25.5 & 2,975 & 26.5 \\
\hline Yes & 1,173 & 60.1 & 2,007 & 61.2 & 3,870 & 64.4 & 7,050 & 62.7 \\
\hline \multicolumn{9}{|c|}{ Pearson chi2(4) $=17.7514, \operatorname{Pr}=0.001$} \\
\hline \multicolumn{9}{|l|}{ Iron is important } \\
\hline No & 483 & 24.7 & 827 & 25.2 & 1,624 & 27 & 2,934 & 26.1 \\
\hline Unsure & 71 & 3.6 & 124 & 3.8 & 177 & 2.9 & 372 & 3.3 \\
\hline Yes & 1,398 & 71.6 & 2,331 & 71 & 4,204 & 70 & 7,933 & 70.6 \\
\hline Pearson chi2 $(4)=10$ & $\operatorname{Pr}=0 . \mathrm{C}$ & & & & & & & \\
\hline
\end{tabular}

Table 1 (continued) 
Table 1 (continued)

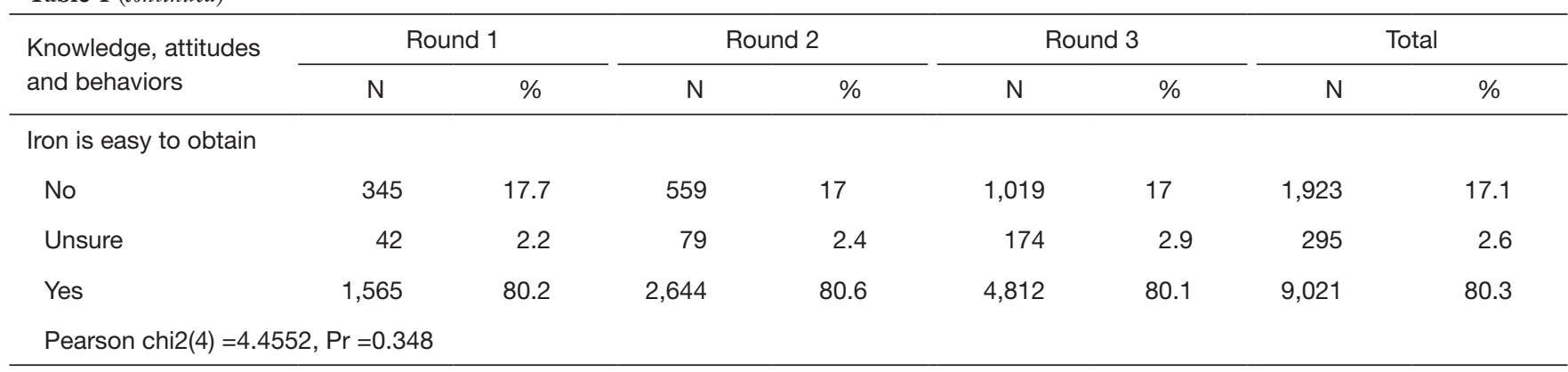

Table 2 Differences in knowledge, attitudes and behaviors by respondent age, baseline data

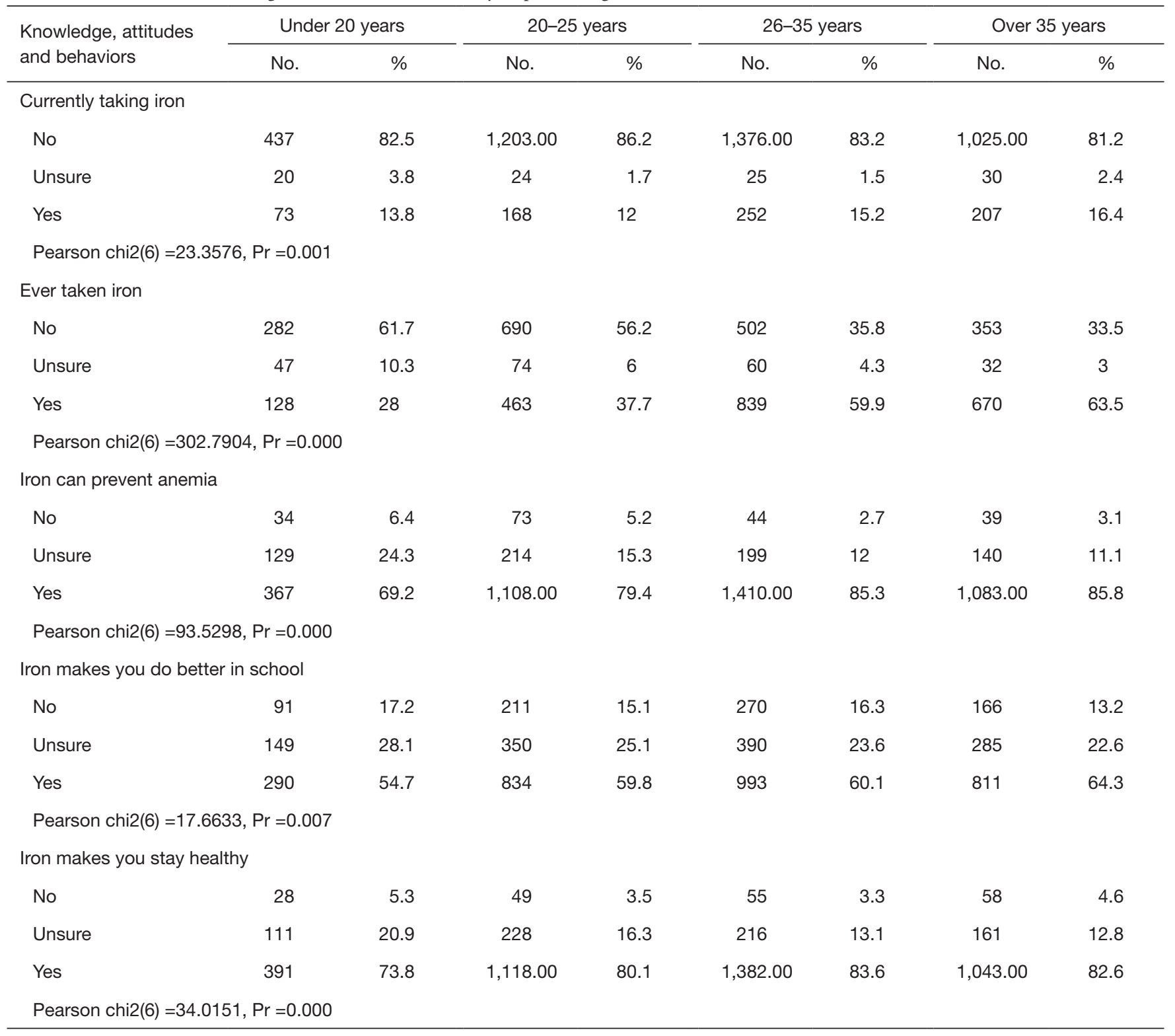

Table 2 (continued) 
Table 2 (continued)

\begin{tabular}{|c|c|c|c|c|c|c|c|c|}
\hline $\begin{array}{l}\text { Knowledge, attitudes } \\
\text { and behaviors }\end{array}$ & \multicolumn{2}{|c|}{ Under 20 years } & \multicolumn{2}{|c|}{ 20-25 years } & \multicolumn{2}{|c|}{$26-35$ years } & \multicolumn{2}{|c|}{ Over 35 years } \\
\hline \multicolumn{9}{|c|}{ Iron can make labor more difficult } \\
\hline No & 239 & 45.1 & 858 & 61.5 & $1,287.00$ & 77.9 & 933 & 73.9 \\
\hline Unsure & 195 & 36.8 & 408 & 29.2 & 261 & 15.8 & 213 & 16.9 \\
\hline \multicolumn{9}{|c|}{ Pearson chi2(6) $=267.5613, \operatorname{Pr}=0.000$} \\
\hline \multicolumn{9}{|c|}{ All Pregnant women should take iron } \\
\hline No & 54 & 10.2 & 69 & 4.9 & 30 & 1.8 & 29 & 2.3 \\
\hline Unsure & 156 & 29.4 & 259 & 18.6 & 123 & 7.4 & 100 & 7.9 \\
\hline \multicolumn{9}{|c|}{ Iron is only for women with anemia } \\
\hline No & 215 & 40.6 & 633 & 45.4 & 806 & 48.8 & 488 & 38.7 \\
\hline Unsure & 164 & 30.9 & 333 & 23.9 & 311 & 18.8 & 219 & 17.4 \\
\hline Yes & 151 & 28.5 & 429 & 30.8 & 536 & 32.4 & 555 & 44 \\
\hline \multicolumn{9}{|c|}{ Pearson chi2(6) $=106.2521, \operatorname{Pr}=0.000$} \\
\hline \multicolumn{9}{|c|}{ All women under 20 should take Iron } \\
\hline No & 103 & 19.4 & 329 & 23.6 & 491 & 29.7 & 374 & 29.6 \\
\hline Unsure & 173 & 32.6 & 507 & 36.3 & 599 & 36.2 & 478 & 37.9 \\
\hline Yes & 367 & 69.2 & $1,021.00$ & 73.2 & $1,181.00$ & 71.4 & 896 & 71 \\
\hline \multicolumn{9}{|c|}{ Pearson chi2(6) $=4.7317, \operatorname{Pr}=0.579$} \\
\hline \multicolumn{9}{|c|}{ Iron makes you gain weight } \\
\hline No & 256 & 48.3 & 826 & 59.2 & $1,132.00$ & 68.5 & 846 & 67 \\
\hline Unsure & 177 & 33.4 & 398 & 28.5 & 387 & 23.4 & 320 & 25.4 \\
\hline Yes & 97 & 18.3 & 171 & 12.3 & 134 & 8.1 & 96 & 7.6 \\
\hline \multicolumn{9}{|c|}{ Pearson $\operatorname{chi} 2(6)=105.4130, \operatorname{Pr}=0.000$} \\
\hline \multicolumn{9}{|c|}{ Iron makes babies too large } \\
\hline No & 183 & 34.5 & 622 & 44.6 & 961 & 58.1 & 722 & 57.2 \\
\hline Unsure & 236 & 44.5 & 560 & 40.1 & 514 & 31.1 & 415 & 32.9 \\
\hline Yes & 111 & 20.9 & 213 & 15.3 & 178 & 10.8 & 125 & 9.9 \\
\hline Pearson chi2 $(6)=143$ & $\operatorname{Pr}=0$ & & & & & & & \\
\hline
\end{tabular}

Table 2 (continued) 
Table 2 (continued)

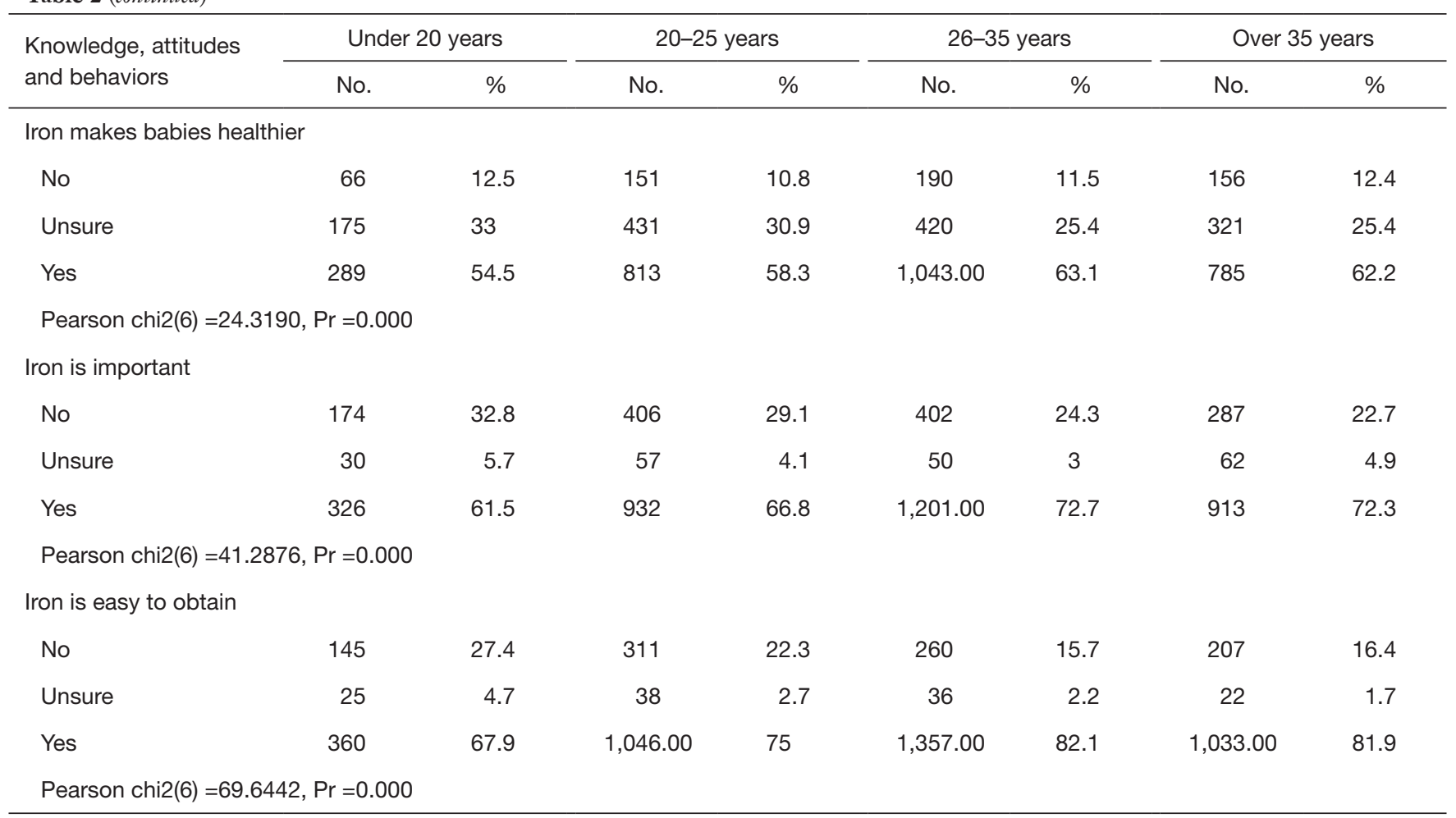

health behaviors than married women or women with children (data not shown). There were some significant differences between Madhya Pradesh and Uttar Pradesh, in no consistent trend.

\section{Intervention impact}

Between baseline and the survey post-campaign 1, controlling for age, Marital status, having children, being currently pregnant and state, women had significantly $(\mathrm{P}<0.05)$ increased odds of saying that all pregnant women should take iron (Table 3). They also had decreased odds of saying that IFA would help girls do better in school, it will make labor and delivery difficult, it is only for women with anemia, and that IFA will make you stronger. Between the baseline and after campaign 2, there was an increased odds that women knew IFA prevents low blood levels and that it makes babies healthier. There was a significantly decreased odds that women reported it would make labor difficult, it is only for women with anemia, it will make you gain weight, and that it would be very easy/easy for them to obtain iron. For most indicators, older age, being married and being currently pregnant were associated with increased odds of answering in the hoped for direction.

\section{Discussion}

The findings here indicate that using platforms such as Facebook may be effective for collecting data from hard to reach populations and developing health-related interventions within those populations. In the case of this study, we were able to reach approximately 3.5 million women in India with a relatively low financial cost. We collected data from a breadth of women in terms of age, Marital status and pregnancy status and were able to identify gaps in efficacy and concerns in self-reported behaviors surrounding a major health issue, anemia, which has continued to impact women in India.

Broadly, the findings about women's IFA awareness and practices in Madhya Pradesh and Uttar Pradesh suggest general knowledge about IFA and anemia is high and that women do value its importance in pregnancy. Respondents were mostly aware of positive attributes of IFA (health of mom and baby), yet misperceptions about negative effects 
Table 3 Change in responses between (I) baseline and post- first campaign and (II) baseline and post-second campaign, odds ratios (standard error)

\begin{tabular}{|c|c|c|}
\hline Knowledge, attitudes and behaviors & $\begin{array}{l}\text { Between baseline and } \\
\text { post-first Campaign }\end{array}$ & $\begin{array}{l}\text { Between baseline and } \\
\text { post-second Campaign }\end{array}$ \\
\hline Have you taken an iron supplement in the last seven days? (Yes) & $1.089(0.0901)$ & $0.978(0.0375)$ \\
\hline Iron supplements prevent low blood levels (anemia). True & $1.066(0.0843)^{\$}$ & $1.114^{\star \star \star}(0.0414)$ \\
\hline Iron supplements help girls do better in school. True & $0.880^{\star \star}(0.0520)$ & $1.009(0.0277)^{\$}$ \\
\hline All pregnant women should take iron supplements. True & $1.234^{\star *}(0.106)$ & $1.057(0.0427)$ \\
\hline Iron supplements are only for women who have anemia. True & $0.885^{\star \star}(0.0533)$ & $0.897^{\star \star \star}(0.0249)$ \\
\hline Taking iron supplements will make you stronger. True & $0.875^{\star \star}(0.0557)$ & $1.000(0.0297)$ \\
\hline $\begin{array}{l}\text { How important is it for you, personally, to take iron supplements? (Very, } \\
\text { somewhat important) }\end{array}$ & $0.951(0.0551)$ & $1.033(0.0276)$ \\
\hline $\begin{array}{l}\text { If you decided to take iron supplements, how easy would it be for you to } \\
\text { obtain tablets in the next week? (Very easy, easy) }\end{array}$ & $1.057(0.0680)^{\$}$ & $0.936^{\star \star}(0.0276)$ \\
\hline
\end{tabular}

Controlling for age, Marital status, number of children, currently pregnant and state. ${ }^{\star \star \star}, \mathrm{P}<0.01,{ }^{\star \star}, \mathrm{P}<0.05,{ }^{*}, \mathrm{P}<0.1 .^{\$}$, not covered at all in that intervention phase.

(large baby, difficult labor, weight gain) persisted for a subset of respondents (about or just under 10\%).

Of concern is the finding that younger women had poorer knowledge and were less likely to be currently or ever have taken iron. Younger women also were more likely to think it would be hard to obtain iron, despite IFA being freely available to adolescents, in addition to pregnant women. Unmarried and nulliparous women were similarly at risk of low knowledge and poorer practices. This lack of awareness of its importance for adolescents may be a barrier to uptake, as has been shown in previous research where education and knowledge about anemia was associated with reductions in anemia (8). Overall, this suggests that outreach and messaging to women before pregnancy should be a priority, including to unmarried women. It may be possible that younger women, such as those in our sample, fall in a gap between programs targeting school aged adolescents and pregnant women, and thus are not receiving appropriate and necessary information. The preconception period is key for improving maternal and child health outcomes and reducing anemia in this time is critical.

The impact of the campaigns delivered through
Facebook, on knowledge, attitudes and behavior is more difficult to disentangle. Each campaign resulted in movement in some indicators in the desired direction (more knowledge, more acceptable, less belief in side effects, more use/awareness), but also in some indicators moving in the direction not desired. Unpacking why each indicator may or may not have changed is difficult because the content of each campaign was different since they were based on the data collected. Specifically, three indicators were only touched on in one or the other campaign. During the first campaign, we noticed the majority of the comments we received were questions about where to find IFA tablets and who to talk to if you think you have anemia. With Rabbithole, we created a light-weight website to drive people to that gave them answers to common questions: http://healthygirlstyle.com/ and created more memes and Gifs that answered these questions directly. A meme is a culturally recognizable image like an image from a Bollywood film that has been previously shared, altered, and then spread often and rapidly by internet users. The image of Hillary Clinton checking her phone while wearing sunglasses is a perfect example of a meme. A Gif is format 
for image files that supports both animated and static images. Here we use Gif to mean images that have a shortanimated element, like a basketball shot into a hoop or a heart beating. Women were less likely to say that it would be easier for them to obtain IFA tablets between baseline and Round 2, suggesting either that knowledge of where to obtain IFA tablets made the women feel that this was more challenging or that the content of the campaigns worked in the opposite direction than we would have hoped. These women may have given more thought to taking IFA tablets, and thus more consideration to the difficulties of obtaining IFA tablets. Second, much more information and depth of content was devoted during campaign two to the idea that Iron supplements prevent low blood levels (anemia), and women had significantly more knowledge about this after the second campaign. Finally, the idea that iron helps girls do better in school was only touched on in phase one, and this only changed significantly between the first two rounds of data collection, but in the wrong direction.

The only two indicators that changed between both campaigns were that iron can make labor/delivery difficult (not true) and that iron supplements are only for women who have anemia (not true), and both of these decreased in odds, which is promising. Both campaigns focused a great deal of content in dispelling the misconception that IFA made labor/delivery difficult and both had the message that women should "find out if you should take iron supplements" in a lot of content, which could lead to the change in the second indicator.

Future interventions that have a more narrow set of information or fewer norms that they are trying to change might have more success in leading to change, and of being measured. Another explanation is that Facebook advertisements alone might not be enough to change behaviors, attitudes and knowledge, and might be needed in concert with other intervention approaches.

\section{Limitations}

This study has data collection-related limitations beyond those mentioned previously related to the intervention itself. First, each round of data collection was from a different group of women. Thus, assessments of individuallevel change are impossible. Also, we do not know with certainty that women saw the ad campaign, how many different ads they saw, or which specific ads they saw. Thus, we do not know the impact of any specific ad or if there is a dose response. Given the relatively short turn around between data collection time points it is unlikely that other factors changed in this time frame that could have impacted knowledge of behaviors (new government programs for example), however, this is a possibility.

Since women self selected into responding to the survey, our results also suffer from selection bias. Women who saw the campaign might have been more likely to respond than women who did not (since anemia was on their mind), which would have led to an overestimation of the effect on the whole population but a better measure of the effect on the women who saw the ads (the "treated"). Parallel data collection activities using traditional data collection methods (household surveys for example) in the same population of women and asking the same set of questions could help us understand if this easy to implement, low cost approach is able to collect high quality, non-biased data. Relatedly, all data was self-reported, and thus we do not know if women's responses were reflective of actual behaviors. Important questions remain, for example we do not know if women are more or less likely to answer honestly over a mobile survey.

Our data collection and intervention approaches required women to have a smartphone, which of course limits its reach to a subset of women who are likely wealthier, more educated, more urban, and have higher levels of knowledge than the general population of women in India. A Facebook-based social and behavioral change campaign is by its very nature limited by the population of people on Facebook. The Indian states of Madhya Pradesh and Uttar Pradesh were selected for this project because there is a large number of MAU on Facebook in our target audience, but it is still a small slice of the total population of young women in these states. Any public health efforts on the Facebook platform should first confirm the use of Facebook among key audiences. Regardless of the size of the audience that accesses to a mobile device today, the audience with mobile devices and using social media is growing exponentially. In 13 years, Facebook has grown to a platform where over 2 billion people come to connect and share over 100 billion messages a day. The communication app WhatsApp, founded in 2009, already has 400 million users in India (27). Other platforms like YouTube, TikTok, and Instagram are also rapidly gaining users in the country.

Finally, the lack of an on-the-ground partner who is currently distributing IFA tablets in the Indian states of Madhya Pradesh and Uttar Pradesh limits our ability to direct people to a source for IFA tablets and our ability to measure uptakes in consumption of IFA tablets. Working with a distribution partner was outside the scope of 
limited intervention. Without one, we referred people to community health workers to get tested for anemia and then, if necessary take IFA tablets.

Despite these limitations, we see opportunities for leveraging and expanding on the findings of this study. First, we believe a similar campaign run in tight collaboration with an on the ground partner focused on driving a measurable increase in IFA consumption would be our ideal next step for this project. In order to do this, it would be critical that we focus the effort in areas where we know that IFA supplements are readily available. For instance, in states where the on-the-ground partner is working to assure that IFA is being provided at schools and health clinics.

Second, a longer campaign that involves Facebook, WhatsApp, and other social media channels could produce more positive effects by reaching more social media users across more channels while reinforcing messages for those who access more than one channel. Doing this could add considerable complexity, yet the measurement and evaluation methodology used here could be repurposed for a multi-channel campaign.

Third, the development and testing of methods for measuring both on-the-ground behaviors and online attitudes in order to better understand how one influences the other could enhance the value of this study. Despite limited resources that prevented this study from reaching on-the-ground respondents, we were able to reach more than 3.5 million women. Understanding how those messages were received, how they were engaged with over time, and if they made their way into on-the-ground conversations represents another pathway for research expansion.

Fourth, this campaign focused on reaching and engaging an audience whose knowledge, beliefs, and behaviors have been of continued concern. Although we did not have a specific influencer strategy, the audience we reached included women who can and do influence other women's health decisions (mothers, mothers in law, teachers, health workers, etc.). Reaching and engaging influencers can positively impact the outcomes of on-social media social and behavioral change communication. Testing a campaign that puts a heavier emphasis on influencers, and includes other influencers such as fathers, husbands, and male teachers, could also produce more holistic findings.

\section{Conclusions}

Social media holds great potential as a means of providing public health information to hard to reach populations. This project is one of many, aiming to provide answers to questions about how to use social media for social change communications. Through this campaign, we were able to demonstrate that it is possible to run effective social behavior change campaigns on social media, particularly in a country where mHealth has shown early promise. We also demonstrated a cost-effective method for leveraging Facebook for measuring and evaluating the efficacy of such interventions. We were able to reach a population of women not easily reached by other interventions (young, unmarried women) who are at high risk of anemia and its health consequences. More work remains to be done before the public health sector will be able to tap the full potential of social media to improve the health and wellbeing of people around the world.

\section{Acknowledgments}

The authors wish to acknowledge Sohail Agha, Pooja Sehgal, Tanya Agrawal, Pooja Halde, Pravesh Dwivedi, and the participants who gave their time to the study.

Funding: This study received funding from the Bill \& Melinda Gates Foundation and funding for intervention testing from Facebook.

\section{Footnote}

Provenance and Peer Review: This article was commissioned by the Guest Editors (Carinne Brody and Sarah Sullivan) for the series "Digital Interventions for Hard-to-reach Populations" published in mHealth. The article was sent for external peer review organized by the Guest Editors and the editorial office.

Conflicts of Interest: All authors have completed the ICMJE uniform disclosure form (available at http://dx.doi. org/10.21037/mhealth-19-237a). The series "Digital Interventions for Hard-to-reach Populations" was commissioned by the editorial office without any funding or sponsorship. NDS reports grants from Bill and Melinda Gates Foundation, during the conduct of the study. SF reports grants from Bill and Melinda Gates Foundation. This project relied on the use of Facebook's apps and services. The company Ms Francis is a member of, Upswell, provides contract services to Facebook's Social Good team. This team aids in the development of resources and provides support to global health organizations and the 
nonprofit sector. DB reports grants from Bill and Melinda Gates Foundation, non-financial support from Facebook, during the conduct of the study; and DB reports grants from Bill and Melinda Gates Foundation. This project relied on the use of Facebook's apps and services. The company DB is a member of, Upswell, provides contract services to Facebook's Social Good team. This team aids in the development of resources and provides support to global health organizations and the nonprofit sector. The authors have no other conflicts of interest to declare.

Ethical Statement: The authors are accountable for all aspects of the work in ensuring that questions related to the accuracy or integrity of any part of the work are appropriately investigated and resolved. This study received human subject approval from the University of California, San Francisco.

Open Access Statement: This is an Open Access article distributed in accordance with the Creative Commons Attribution-NonCommercial-NoDerivs 4.0 International License (CC BY-NC-ND 4.0), which permits the noncommercial replication and distribution of the article with the strict proviso that no changes or edits are made and the original work is properly cited (including links to both the formal publication through the relevant DOI and the license). See: https://creativecommons.org/licenses/by-nc-nd/4.0/.

\section{References}

1. Kassebaum NJ, Jasrasaria R, Naghavi M, et al. A systematic analysis of global anemia burden from 1990 to 2010. Blood 2014;123:615-24.

2. Nguyen PH, Scott S, Avula R, et al. Trends and drivers of change in the prevalence of anaemia among 1 million women and children in India, 2006 to 2016. BMJ Glob Health [Internet]. 2018 Oct 1 [cited 2019 Nov 20];3(5). Available online: https://gh.bmj.com/content/3/5/e001010

3. International Institute of Population Sciences. National Family Health Survey (NFHS-4) India 2015-16. International Institue of Population Sciences; 2017. Available online: https://dhsprogram.com/pubs/pdf/ FR339/FR339.pdf

4. Di Renzo GC, Spano F, Giardina I, et al. Iron Deficiency Anemia in Pregnancy. Womens Health (Lond) 2015;11:891-900.

5. Diamond-Smith NG, Gupta M, Kaur M, et al. Determinants of Persistent Anemia in Poor, Urban
Pregnant Women of Chandigarh City, North India: A Mixed Method Approach. Food Nutr Bull 2016;37:132-43.

6. Katiyar SP. Gender Disparity in Literacy in India. Soc Change 2016;46:46-69.

7. Kalaivani K, Ramachandran P. Time trends in prevalence of anaemia in pregnancy. Indian J Med Res 2018;147:268-77.

8. Siddiqui MZ, Goli S, Reja T, et al. Prevalence of Anemia and Its Determinants Among Pregnant, Lactating, and Nonpregnant Nonlactating Women in India. SAGE Open 2017;7:2158244017725555.

9. Bharati P, Shome S, Chakrabarty S, et al. Burden of Anemia and its Socioeconomic Determinants among Adolescent Girls in India. Food Nutr Bull 2009;30:217-26.

10. The burden of iron-deficiency anaemia among women in India: how have iron and folic acid interventions fared? Rai RK, Fawzi WW, Barik A, Chowdhury A - WHO SouthEast Asia J Public Health [Internet]. [cited 2019 Nov 20]. Available online: http://www.who-seajph.org/article. asp? issn=2224-3151; year=2018; ;olume $=7$;issue $=1$; spage $=1$ 8; epage $=23$; aulast $=$ Rai

11. Paayal C, Ganesh U, Shaantanu D. Indian Perspective on Clinical Aspects, Usage, and Guidelines of Folic Acid. J Obstet Gynaecol India 2014;64:328-31.

12. Varghese JS, Swaminathan S, Kurpad AV, et al. Demand and supply factors of iron-folic acid supplementation and its association with anaemia in North Indian pregnant women. PLoS One 2019;14:e0210634.

13. Kumar A. National nutritional anaemia control programme in India. Indian J Public Health 1999;43:3-5, 16.

14. Aguayo VM, Paintal K, Singh G. The Adolescent Girls' Anaemia Control Programme: a decade of programming experience to break the inter-generational cycle of malnutrition in India. Public Health Nutr 2013;16:1667-76.

15. Diamond-Smith N, Raj A, Prata N, et al. Associations of women's position in the household and food insecurity with family planning use in Nepal. PLoS One 2017;12:e0176127.

16. Stephenson J, Heslehurst N, Hall J, et al. Before the beginning: nutrition and lifestyle in the preconception period and its importance for future health. Lancet 2018;391:1830-41.

17. Sedlander E, Long M, Mohanty S, et al. Moving Beyond Individual Barriers and Identifying Multi-level Strategies to Address Anemia in Rural India. BMC Public Health 2020;20:457.

18. Galloway R, Dusch E, Elder L, et al. Women's perceptions of iron deficiency and anemia prevention and control in eight developing countries. Soc Sci Med 2002;5 5:529-44. 
19. Narasimhan P, Bakshi A, Kittusami S, et al. A customized $\mathrm{m}$-Health system for improving Tuberculosis treatment adherence and follow-up in south India. Health Technol 2014;4:1-10.

20. Pfammatter A, Spring B, Saligram N, et al. mHealth Intervention to Improve Diabetes Risk Behaviors in India: A Prospective, Parallel Group Cohort Study. J Med Internet Res 2016;18:e207.

21. Modi D, Gopalan R, Shah S, et al. Development and formative evaluation of an innovative $\mathrm{mHealth}$ intervention for improving coverage of community-based maternal, newborn and child health services in rural areas of India. Glob Health Action 2015;8:26769.

22. Majumdar A, Kar SS, S GK, et al. mHealth in the Prevention and Control of Non-Communicable Diseases in India: Current Possibilities and the Way Forward. J Clin Diagn Res 2015;9:LE06-LE10.

23. Sharma M, Yadav K, Yadav N, et al. Zika virus pandemicanalysis of Facebook as a social media health information

doi: $10.21037 /$ mhealth-19-237a

Cite this article as: Diamond-Smith N, Holton AE, Francis $\mathrm{S}$, Bernard D. Addressing anemia among women in India-an informed intervention using Facebook Ad manager. mHealth 2020;6:39. platform. Am J Infect Control 2017;45:301-2.

24. Byron P, Albury K, Evers C. "It would be weird to have that on Facebook": young people's use of social media and the risk of sharing sexual health information. Reprod Health Matters 2013;21:35-44.

25. Clement J. Leading countries based on number of Facebook users as of October 2019 (in millions) [Internet]. 2019. Available online: https://www.statista.com/ statistics/268136/top-15-countries-based-on-number-offacebook-users/

26. Bernard D, McCullough C, Francis S, et al. Facebook Powered Measurement and Evaluation for Iron Folic Acid Health Intervention in India. Gates Open Res 2019;3:1536.

27. Singh $M$. WhatsApp reaches 400 million users in India, its biggest market [Internet]. 2019. Available online: https:// techcrunch.com/2019/07/26/whatsapp-india-users-400million/ 